\title{
Self-reported and clinically evident gingival bleeding and impact on oral health-related quality of life in young adolescents: a comparative study
}

\author{
Folake B. Lawal ${ }^{1,2,3}$, Elizabeth B. Dosumu ${ }^{1,2}$ \\ 1. Department of Periodontology and Community Dentistry, University of Ibadan, Ibadan, Nigeria \\ 2. Department of Periodontology and Community Dentistry, University College Hospital, Ibadan, Nigeria \\ 3. Consortium for Advanced Research Training in Africa (CARTA), APHRC, Nairobi, Kenya
}

Correspondence: Folake B. Lawal (folakemilawal@yahoo.com)

\begin{abstract}
Background
Very little is known about how self-reported gingival bleeding affects the oral health-related quality of life in adolescents compared with clinically evident bleeding. This study aimed to compare the impact of self-reported gingival bleeding and clinically evident gingival bleeding on the oral health-related quality of life in young adolescents.

Methods

This was a cross-sectional study involving 976 students (aged 10-14 years) in randomly selected primary schools in Ibadan. Data were obtained by oral examination and completion of the Child Oral Impact on Daily Performance Questionnaire. Data were analysed with SPSS version 24. The Mann Whitney $U$ test was used to determine the association between gingival bleeding and the quality of life.

Results

The mean age of the participants was $11.4 \pm 1.3$ years. Almost half $(48.3 \%)$ of the participants reported gingival bleeding during tooth cleaning while the gingiva of $534(54.7 \%)$ participants bled on examination. Pupils with self-reported bleeding suffered a significantly greater impact on their overall quality of life than those without self-reported bleeding (mean ranks: 528.1 vs. $451.6, P<0.001$ ). For pupils with self-reported bleeding, there were higher impacts on all domains relating to quality of life than those who did not report bleeding (eating: mean ranks=521.0 vs. 458.2 ; speaking: 502.2 vs. 475.8 ; teeth cleaning: 522.7 vs. 456.7 ; sleeping: 497.7 vs. 456.7 ; showing teeth/smiling: 503.4 vs. 474.6 ; emotional stability: 501.1 vs. 476.8 ; school work: 492.4 vs. 484.9 , and enjoying contact with other children: 494.0 vs. 483.4). There was no statistically significant association between clinically evident bleeding and impacts on the quality of life $(P=0.272)$.

Conclusion

Almost half of the students reported gingival bleeding while cleaning their teeth and over 50\% experienced gingival bleeding on probing. Those with self-reporting of gingival bleeding had greater impacts on oral health-related quality of life compared with those with clinically evident bleeding.
\end{abstract}

Abstract

Key Words; Adolescents, gingivitis, oral health, quality of life, periodontal diseases

\section{Introduction}

Gingival bleeding is one of the earliest signs of gingival inflammation, a common condition among adolescents. Gingival inflammation is often considered a major symptom and clinical indicator of periodontal disease ${ }^{1}$. In its commonest form, this condition is associated with dental plaque and may be due to a wide array of systemic factors ${ }^{1}$. Plaque-induced bleeding from the gingiva is a public health concern because of the high global prevalence of periodontal diseases $^{2}$. The prevalence of gingival bleeding among adolescents varies across the world and has been found to range from $37.4 \%$ to $99.0 \%$ in different populations ${ }^{3-7}$. In Nigeria, the prevalence of this condition in adolescents in an urban setting was reported to be $54.3 \%$.

Clinically evident gingival bleeding (CGB) affects the oral health-related quality of life (OHRQoL) in adolescents ${ }^{6}$. However, it remains uncertain if this is the case among adolescents in Nigeria. This becomes important in view of the high prevalence of this condition among adolescents and the fact that this particular population exhibit poor oral healthseeking behavior ${ }^{8,9}$. Although this is an obvious pointer for the need to promote oral health among adolescents in the country, there is, however, a paucity of information relating to the burden of this condition with regards to initiating a suitable planning process for interventions to address this public health problem. Understanding the perception of adolescents on how gingival bleeding, as reported by specific individuals, affects their daily activities is vital if we are to plan such programs. Furthermore, the self-perception of a condition and the impact of the condition on the quality of life are important epidemiological measures in describing the burden of a condition for health interventions ${ }^{10}$. In addition, gingival bleeding is often perceived as a feature of tooth cleaning by adolescents in low income countries such as Nigeria ${ }^{11}$. This is an additional indicator for the need to promote oral health; this is critical at the stage of adolescence as this practice can prevent periodontal diseases in later years ${ }^{12}$.

Moreover, very little is known about how self-reported gingival bleeding (SRGB) affects the OHRQoL of adolescents compared with CGB. This study therefore compared the impact of SRGB and CGB on the OHRQOL in young adolescents in Ibadan, Southwest Nigeria. 


\section{Methods}

This was a cross-sectional study conducted among adolescents in the fifth and sixth grades of randomly selected public primary schools in Ibadan, Nigeria. Ibadan is the capital city of Oyo State, Southwestern Nigeria and is the largest city in sub-Saharan Africa. The city is stratified into metropolitan areas, which are more developed, and non-metropolitan regions. A sample size of 895 was obtained for the study, calculated using a sample size formula for cross-sectional studies $^{13}$ at a prevalence rate of $54.3 \%$ for $\mathrm{CGB}^{8}$ and a $3.5 \%$ degree of error. A non-response rate of $20 \%$ was added to the calculated sample size in order to accommodate for nonresponders or withdrawal from the study at any stage. This resulted in a total of 973 students as the minimum sample size for the study.

The study participants were recruited from 19 public primary schools that were selected using a systematic sampling technique from a list featuring 338 schools within the metropolis of Ibadan. A proportionate sample of 20-30 students was selected from each of the grade five and six classes in each school using a table of random numbers. The study aimed to address an early adolescence group aged between 10 and 14 years ${ }^{14}$. This age group was selected to address young adolescents who were still in the process of establishing autonomy in the psychosocial development stage $^{15}$. In addition, adolescents in this age group are at a stage when they are beginning to shape their own behaviour, thus making them targets for oral health promotion; such strategies will last into late adolescence and adulthood ${ }^{14,15}$, particularly as the prevalence of periodontal disease increases with age. This age group is more likely seen in grades five and six in public schools of our country, hence we decided to focus on these particular grades.

Permission to carry out the study was obtained from the State Ministry of Education and the State Universal Education Board before visiting each school. Ethical approval was obtained from the State Ethics Review Board (Reference: AD 13/479/649).

Permission was obtained from the head teacher in each school and the purpose of the study was explained to both the head teacher and class teachers. This was followed by the selection of students from the two classes (grades five and six). The selected students were gathered together in a classroom or school hall and the purpose of the study was explained to them. We answered any questions that the students put forward. Each student was given a consent form written in both English and Yoruba languages to take home to obtain consent from their parents. The informed consent form was translated to ensure that all parents, irrespective of their educational qualifications, were informed of the purpose of the research and the processes involved. The study recruited only students that returned signed consent forms; those who did not give consent or were ill at the time that data were collected were excluded from the study. Data were obtained with a questionnaire and an oral examination; these were administered by an interviewer and a dentist, respectively.

The questionnaire was translated into the local language by two independent researchers versed in both English and Yoruba languages. The Yoruba version of the questionnaire was translated back into English language by another independent scholar versed in English and Yoruba languages. The translated questionnaire was pre-tested among 50 pupils in a school that was not included in the study. The pretest was used to investigate the ease of administering the questionnaire and the comprehensibility of the questions by the students. The questionnaire comprised 13 questions under three sections. Section A assessed biodata for each participant, including age at last birthday, sex, father's occupation, and mother's occupation. The occupation was classified into skilled, unskilled, and dependent, according to a modification of the Office of Population Census and Survey ${ }^{16}$. We recorded the higher occupational class of either the father or the mother, as appropriate. In addition, SRGB was assessed by a single item question: "Does your gum bleed while brushing"; the responses were "Yes" (to include always, often and sometimes), or "No". Section C assessed the OHRQoL of the participants using the Child Oral Impact on Daily Performances (C-OIDP) index.

The C-OIDP has been validated and used previously in Nigeria $^{17,18}$. This questionnaire features eight questions and a 3-point Likert scale for frequency and severity response scales. The eight daily performances that were assessed included difficulty in eating and enjoying food, speaking and pronouncing words, teeth cleaning, sleeping and relaxing, emotional stability, smiling/showing teeth, studying, and social contacts, during the three months preceding the study. The response scale consisted of a frequency scale and a severity scale from 0 (never) to 3 . Each performance score was calculated by multiplying the frequency score by the severity score and a total score was generated by the summation of the eight performance scores; the performance score ranged from 0 to 72 .

Oral examination was conducted by two trained and calibrated dentists with the help of trained research assistants who recorded the oral examination findings into the assessment forms. Inter-examiner variability was assessed by the random examination of 50 students during the study; the interexaminer variability was 0.9 . Oral examination was conducted in a classroom with students seated upright on a chair with natural lighting serving as the source of illumination. A Sterile World Health Organization Community Periodontal Index probe and a dental mirror were used for all oral examinations. To ensure privacy, we examined one student at a time. A teacher was present as a guardian during the oral examination. Gingival bleeding was determined using the gingival index ${ }^{19}$. During gentle probing of the four surface areas of the index teeth ${ }^{19}$, the gingival index was charted as 0 , absence of inflammation; 1 , mild gingivitis (no bleeding, slight change in colour and little change in texture of the gingiva); 2, moderate gingivitis (bleeding on probing, moderate glazing, redness, edema, and hypertrophy); and 3, severe gingivitis (tendency for spontaneous bleeding, marked redness and hypertrophy) ${ }^{19}$. Gingival bleeding was recorded as being present if the participant had a gingival index score of 2 (moderate) or 3 (severe). We also recorded the presence or absence of orthodontic appliances.

Data were analysed with SPSS version 23 (IBM). Interexaminer variability was assessed by Kappa statistics. The internal consistency of the C-OIDP was evaluated using Cronbach's alpha. Categorical data were summarized by frequencies and percentages. Continuous variables were summarized by means and standard deviation. The Shapiro Wilk test was used to evaluate the normality of the C-OIDP scores $^{20}$. The association between participant biodata and gingival bleeding was conducted using the $\chi$-square test and bivariate analysis. Logistic regression was used for 
multivariate analysis for variables that were proven to be statistically significant by bivariate analysis; unadjusted and adjusted odd ratios are presented. The Mann Whitney $U$ test was used to evaluate the association between C-OIDP scores and gingival bleeding. The level of statistical significance was set at $P<0.05$.

\section{Results}

A total of 976 students participated in this study. The age of the participants ranged from 10 to 14 years with a mean age of $11.4 \pm 1.3$ years; $45.6 \%$ were females. The parents of $92.8 \%$ of the participants were in the unskilled occupational class (Table 1).

Almost half of the participants $(48.3 \%)$ reported gingival bleeding during tooth cleaning and $54.7 \%$ of participants experienced gingival bleeding on clinical examination. None of the participants had an orthodontic appliance. Cronbach's alpha for the C-OIDP measure was 0.91 .

The C-OIDP score ranged from 0 to 63 with a median of 0.0 and a mean score of $2.5 \pm 7.5$. Normality tests of data showed that C-OIDP scores were not normally distributed (Shapiro Wilk statistic $=0.385, P<0.001$ ).

The mean C-OIDP score was 4.0 \pm 9.6 among those with SRGB compared with $1.1 \pm 4.2$ for those without SRGB.
Table 1. Characteristics of the participants.

\begin{tabular}{lll}
\hline Variable & Frequency & $\%$ \\
\hline Sex & & \\
Male & 531 & 54.4 \\
Female & 445 & 45.6 \\
Age (years) & & \\
$10-11$ & 568 & 58.2 \\
$12-14$ & 408 & 41.8 \\
Parent's occupational class & & \\
Skilled & 44 & 4.5 \\
Unskilled & 906 & 92.8 \\
Dependent & 26 & 2.7 \\
Self-reported gingival bleeding & & \\
Present & 471 & 48.3 \\
Absent & 505 & 51.7 \\
Clinically evident gingival & & \\
bleeding & & \\
Present & 534 & 54.7 \\
Absent & 442 & 45.2 \\
\hline
\end{tabular}

Table 2. Self-reported gingival bleeding, clinically evident gingival bleeding, and sociodemographic characteristics.

\begin{tabular}{|c|c|c|c|c|c|c|c|c|}
\hline & \multicolumn{4}{|c|}{ Self-reported gingival bleeding } & \multicolumn{4}{|c|}{ Clinically evident gingival bleeding } \\
\hline Variables & $\begin{array}{l}\text { Present } \\
\mathrm{n}(\%)\end{array}$ & $\begin{array}{l}\text { Absent } \\
\mathrm{n}(\%)\end{array}$ & $x^{2}$ & $P$ value & $\begin{array}{l}\text { Present } \\
\mathrm{n}(\%)\end{array}$ & $\begin{array}{l}\text { Absent } \\
\mathrm{n}(\%)\end{array}$ & $x^{2}$ & $P$ value \\
\hline \multicolumn{9}{|l|}{ Sex } \\
\hline Male & $253(47.6)$ & $278(52.4)$ & 0.175 & 0.676 & $313(58.9)$ & $218(41.1)$ & 8.419 & $0.004^{*}$ \\
\hline Female & $216(49.0)$ & $227(51.0)$ & & & $221(49.7)$ & $224(50.3)$ & & \\
\hline \multicolumn{9}{|l|}{ Age (years) } \\
\hline $10-11$ & $227(48.8)$ & $291(51.2)$ & 0.141 & 0.707 & $290(51.1)$ & $278(48.9)$ & 7.333 & $0.007^{*}$ \\
\hline $12-14$ & $194(47.5)$ & $214(52.5)$ & & & $244(59.8)$ & $164(40.2)$ & & \\
\hline \multicolumn{9}{|c|}{ Occupational class } \\
\hline Skilled & $17(38.6)$ & $27(61.4)$ & 3.471 & 0.176 & $17(38.6)$ & $27(61.4)$ & 6.850 & $0.033^{*}$ \\
\hline Unskilled & $438(48.3)$ & $468(51.7)$ & & & $499(55.1)$ & $407(44.9)$ & & \\
\hline Dependent & $16(61.5)$ & $10(38.5)$ & & & $18(69.2)$ & $8(30.8)$ & & \\
\hline
\end{tabular}

*Statistically significant $(P<0.05)$.

Table 3. Logistic regression of the association between clinically evident gingival bleeding and participant biodata.

\begin{tabular}{llllllll}
\hline Variable & Category & \multicolumn{3}{c}{ Unadjusted } & \multicolumn{3}{c}{ Adjusted } \\
& & $\mathrm{OR}$ & $\mathrm{Cl}$ & $\mathrm{P}$ value & $\mathrm{OR}$ & $\mathrm{Cl}$ & $\mathrm{P}$ value \\
\hline Age (years) & $12-14$ & 1.4 & $1.1-1.8$ & $0.007^{*}$ & 1.4 & $1.1-1.8$ & $0.013^{*}$ \\
& $10-11$ & & & & & & \\
Sex & Male & 1.5 & $1.1-1.9$ & $0.004^{*}$ & 1.4 & $1.1-1.8$ & $0.007^{*}$ \\
& Female & & & & & & \\
Parent occupational Class & Skilled & 0.3 & $0.1-0.8$ & $0.015^{*}$ & 0.3 & $0.1-0.8$ & $0.017^{*}$ \\
& $\begin{array}{l}\text { Unskilled } \\
\text { Dependents }\end{array}$ & 0.5 & $0.2-1.3$ & 0.158 & 0.6 & $0.2-1.4$ & 0.280 \\
& & & & & & \\
\hline
\end{tabular}

The mean C-OIDP scores were $2.3 \pm 7.2$ and $2.7 \pm 7.8$ for those with and without gingival bleeding on probing, respectively. The was no difference between the participants distributions with respect to sociodemographic groups and SRGB (Table 2). On the other hand, differences existed in relation to sex, age, the occupational class of the parents, and CGB (Table 2). Participants aged 12-14 years were more likely to be clinically diagnosed with gingival bleeding than those aged $10-11$ years (odds ratio $[\mathrm{OR}]=1.4 ; 95 \%$ confidence interval $[\mathrm{CI}]=1.1-1.8, P=0.013)$. 
Table 3. Logistic regression of the association between clinically evident gingival bleeding and participant biodata.

\begin{tabular}{lllccccc}
\hline Variable & Category & \multicolumn{4}{c}{ Unadjusted } & \multicolumn{3}{c}{ Adjusted } \\
& & OR & Cl & P value & OR & Cl & P value \\
\hline Age (years) & $12-14$ & 1.4 & $1.1-1.8$ & $0.007^{*}$ & 1.4 & $1.1-1.8$ & $0.013^{*}$ \\
Sex & $10-11$ & & & & & & \\
& Male & 1.5 & $1.1-1.9$ & $0.004^{*}$ & 1.4 & $1.1-1.8$ & $0.007^{*}$ \\
Parent occupational Class & Female & & & & & & \\
& Skilled & 0.3 & $0.1-0.8$ & $0.015^{*}$ & 0.3 & $0.1-0.8$ & $0.017^{*}$ \\
& $\begin{array}{l}\text { Unskilled } \\
\text { Dependents }\end{array}$ & 0.5 & $0.2-1.3$ & 0.158 & 0.6 & $0.2-1.4$ & 0.280 \\
& & & & & & \\
\hline
\end{tabular}

Table 4. Impact of self-reported gingival bleeding and clinically evident gingival bleeding on oral health-related quality of life.

\begin{tabular}{|c|c|c|c|c|c|c|c|c|}
\hline \multirow[b]{2}{*}{ C-OIDP item } & \multicolumn{4}{|c|}{ Self-reported gingival bleeding } & \multicolumn{4}{|c|}{ Clinically evident gingival bleeding } \\
\hline & $\begin{array}{l}\text { Mean } \\
\text { rank }\end{array}$ & $U$ & Z & $P$ value & $\begin{array}{l}\text { Mean } \\
\text { rank }\end{array}$ & $U$ & Z & $P$ value \\
\hline \multicolumn{9}{|l|}{ Eating } \\
\hline Present & 521.0 & 103603.0 & -5.649 & $<0.001^{*}$ & 484.1 & 115672.5 & -0.866 & 0.386 \\
\hline Absent & 458.2 & & & & 493.8 & & & \\
\hline \multicolumn{9}{|l|}{ Speaking } \\
\hline Present & 502.2 & 112487.5 & -3.572 & $<0.001^{*}$ & 485.1 & 116191.0 & -1.015 & 0.310 \\
\hline Absent & 475.75 & & & & 492.6 & & & \\
\hline \multicolumn{9}{|l|}{ Cleaning teeth } \\
\hline Present & 522.7 & 102836.0 & -6.194 & $<0.001^{*}$ & 482.1 & 114619.5 & -1.312 & 0.190 \\
\hline Absent & 456.7 & & & & 496.2 & & & \\
\hline \multicolumn{9}{|l|}{ Sleeping } \\
\hline Present & 497.7 & 114595.0 & -2.739 & $0.006^{*}$ & 486.7 & 117043.0 & -0.616 & 0.538 \\
\hline Absent & 456.7 & & & & 490.7 & & & \\
\hline \multicolumn{9}{|l|}{ Smiling } \\
\hline Present & 503.4 & 111903.5 & -4.065 & $<0.001^{*}$ & 484.0 & 115615.0 & -1.394 & 0.163 \\
\hline Absent & 474.6 & & & & 493.9 & & & \\
\hline \multicolumn{9}{|c|}{ Emotional stability } \\
\hline Present & 501.1 & 113000.5 & -4.301 & $<0.001^{*}$ & 484.8 & 116057.5 & -1.425 & 0.154 \\
\hline Absent & 476.8 & & & & 492.9 & & & \\
\hline \multicolumn{9}{|l|}{ School work } \\
\hline Present & 492.4 & 117106.5 & -2.084 & $0.037^{*}$ & 486.6 & 116991.5 & -1.175 & 0.240 \\
\hline Absent & 484.9 & & & & 490.8 & & & \\
\hline \multicolumn{9}{|l|}{ Social contact } \\
\hline Present & 494.0 & 116338.0 & -2.675 & $<0.001^{*}$ & 485.1 & 116190.0 & -1.892 & 0.059 \\
\hline Absent & 483.4 & & & & 492.6 & & & \\
\hline \multicolumn{9}{|c|}{ Total OIDP score } \\
\hline Present & 528.1 & 100290.5 & -6.207 & $<0.001^{*}$ & 482.4 & 114730.0 & -1.098 & 0.272 \\
\hline Absent & 451.6 & & & & 495.9 & & & \\
\hline
\end{tabular}

CGB, clinically evident gingival bleeding; C-OIDP, child oral impact on daily performances; OIDP, oral impact on daily performances; SRGB, selfreported gingival bleeding. *Statistically significant $(\mathrm{P}<0.05)$.

Male participants were also more likely to have CGB than females, the OR was only slightly reduced $(\mathrm{OR}=1.4 ; 95 \%$ $\mathrm{CI}=1.1-1.8 ; P=0.007)$ after adjusting for other demographic factors (Table 3). Participants whose parents were skilled workers were less likely to have $\mathrm{CGB}$ than others $(\mathrm{OR}=0.3$; $95 \% \mathrm{CI}=0.1-0.8 ; P=0.015)$; this did not change after adjustment for other demographic variables (Table 3).
Participants who had SRGB had higher mean ranks of statistically significant impacts on the overall OHRQoL compared with those who did not report gingival bleeding (528.1 vs. 451.6, $P<0.001$ ) (Table 4). Similarly, those who had SRGB had more statistically significant impacts for all of the domains of the C-OIDP (eating, speaking, teeth cleaning, showing teeth/smiling, emotional stability, sleeping, school https://dx.doi.org/10.4314/mmj.v33i2.7 
work, and enjoying contact with other children) than others (Table 4). Tooth cleaning and eating were the daily activities that were most frequently affected by gingival bleeding (Table 4).

Participants with CGB had lower but non-significant impacts on their quality of life than those without CGB (mean ranks: 482.4 vs. $492.6, P=0.272$ ). There were no statistically significant associations between CGB and any of the domains of the C-OIDP (Table 4).

\section{Discussion}

The study assessed SRGB and CGB and their relative impact on OHRQoL in young adolescents in Ibadan, Nigeria. Our results showed that over $50 \%$ of the participants had CGB; these findings were similar to those reported previously for Nigeria ${ }^{8}$. However, higher proportions than that observed in this study have been reported among 12 -year-olds in Brazil $^{4}$, and among adolescents in Laos ${ }^{3}$, Thailand ${ }^{6}$, and Greece 5 . On the other hand, a lower proportion $(25.9 \%)$ was previously reported among adolescents in Georgia ${ }^{21}$. Disease distribution, coupled with an awareness of oral health, may explain the different prevalence rates reported in these earlier studies.

Less than $50 \%$ of the participants reported gingival bleeding while brushing. Males were more likely to have CGB. This is similar to the findings reported by other studies, $5,722,23$. The more positive attitude of females to health, generally, compared with males may have contributed to this finding. A higher proportion of older participants had CGB compared with younger participants. This finding was corroborated by the fact that the prevalence of periodontal diseases increases with age ${ }^{12,22}$. Furthermore, participants whose parents belonged to lower occupational classes were also more likely to have CGB. Socioeconomic class, with its dominant effect on oral health, has been extensively discussed ${ }^{5,10}$. The poorer oral health of adolescents and individuals from lower social classes could arise from suboptimal oral practices and malnutrition, in addition to inaccessibility to dental care services.

CGB was not associated with the OHRQoL of adolescents in this study. In addition, CGB had lower impacts on participants OHRQoL. Our findings are in contrast to other reports among Thai adolescents aged 12 and 15 years where gingivitis caused greater impacts on OHRQoL ${ }^{6}$. Furthermore, a higher odds of impaired OHRQoL was noted among children with CGB compared with those without gingival bleeding, as reported by other authors ${ }^{24-26}$. However, a previous study also published findings that were similar to those reported herein ${ }^{27}$. The differences across these studies may be attributed to the perception of the participants involved in these studies. Another contributor may be the chronicity of the condition, which exists without pain except in acute cases. The role of pain and oral diseases on OHRQoL has been previously documented ${ }^{17}$.

Incongruous with our findings related to CGB among young adolescents, SRGB was associated with greater impacts on the overall quality of life. In addition, participants with SRGB had higher impacts on OHRQoL which affected all of the C-OIDP domains. The impact of SRGB on OHRQoL has been documented in a previous study ${ }^{28}$. However, none of the previous studies documented how daily activities could be influenced by SRGB. Tooth cleaning and eating were the daily activities that were most frequently reported to be affected by SRGB. The inflammation associated with such bleeding may be responsible for the effect on tooth cleaning and eating. Similarly, the sight of blood may also be associated with fear, which could further hinder adequate tooth cleaning, thus leading to poorer levels of oral hygiene. Maintaining social contact or performing school work were the activities that were least affected by gingival bleeding. These data showed that gingival bleeding has less impact on such activities. Social activities may not be as impaired as other activities unless they are associated with dental appearance; this factor is considered to be important among adolescents and many individuals.

This study had limitations that need to be considered when interpreting our findings. First, this study featured a cross-sectional design; as such, cause-effect relationships should be interpreted with caution. However, the study has provided information relating to SRGB and CGB to further describe the burden of gingival bleeding on the OHRQoL of adolescents. Secondly, the study participants were adolescents from public secondary schools; this makes it difficult to generalize our findings to private schools. This was, however, the intention of the study due to the high prevalence of gingival bleeding among adolescents from low socioeconomic classes; these are predominantly seen in public schools. Findings from this study could be further enhanced by using quantitative methods to analyse the perception of adolescents with regards to gingival bleeding and other symptoms of plaque-related periodontal diseases.

\section{Conclusion}

Almost half of the students investigated reported gingival bleeding while cleaning their teeth and over $50 \%$ experienced gingival bleeding on probing. The self-reporting of gingival bleeding resulted in greater impacts on OHRQoL compared with clinically evident bleeding.

\section{Conflict of interest}

The authors do not have any conflicts of interest regarding the conduct of the research or publication of the findings.

\section{Acknowledgements}

This research was supported by the Consortium for Advanced Research Training in Africa (CARTA). CARTA is jointly led by the African Population and Health Research Center and the University of the Witwatersrand and funded by the Carnegie Corporation of New York (Grant number: B 8606.R02), Sida (Grant number: 54100113), the DELTAS Africa Initiative (Grant number: 107768/Z/15/Z) and Deutscher Akademischer Austauschdienst (DAAD). The DELTAS Africa Initiative is an independent funding scheme of the African Academy of Sciences (AAS)'s Alliance for Accelerating Excellence in Science in Africa (AESA) and supported by the New Partnership for Africa's Development Planning and Coordinating Agency (NEPAD Agency) with funding from the Wellcome Trust (UK) and the UK government. The statements made and views expressed herein are solely the responsibility of the authors.

\section{References}

1. Mârţu S, Solomon S, Potârnichie O, et al. Evaluation of the prevalence of the periodontal disease versus systemic and local risk factors. Int $\mathrm{J}$ Med Dent. 2013;3(3):212-8.

2. Botero JE, Rösing CK, Duque A, Jaramillo A, Contreras A. Periodontal disease in children and adolescents of Latin America. Periodontol 2000. 2015;67(1):34-57. doi: 10.1111/prd.12072. 
3. Jurgensen N, Petersen PE. Oral health and the impact of sociobehavioural factors in a cross sectional survey of 12-year old school children in Laos. BMC Oral Health. 2009;9:29. doi: 10.1186/14726831-9-29.

4. Tomazoni F, Vettore MV, Zanatta FB, Tuchtenhagen S, Moreira CH, Ardenghi TM. The associations of socioeconomic status and social capital with gingival bleeding among schoolchildren. J Public Health Dent. 2017;77(1):21-9. doi: 10.1111/jphd.12166.

5. Chrysanthakopoulos NA. Prevalence of gingivitis and associated factors in 13-16-year-old adolescents in Greece. Eur J Gen Dent. 2016;5(2):58-64.

6. Krisdapong S, Prasertsom P, Rattanarangsima K, Sheiham A Relationships between oral diseases and impacts on Thai schoolchildren's quality of life: evidence from a Thai national oral health survey of 12 and 15-year-olds. Community Dent Oral Epidemiol. 2012;40(6):550-9.

7. Olczak-Kowalczyk D, Gozdowski D, Kaczmarek U. Oral health in Polish fifteen-year-old adolescents. Oral Health Prev Dent. 2019;17(2):139-46.

8. Popoola BO, Dosumu EB, Ifesanya JU. Periodontal status and treatment need among adolescents in Ibadan, Southwestern Nigeria. Braz J Oral Sci. 2015;14(2):117-21.

9. Lawal FB, Oke GA. Clinical and sociodemographic factors associated with oral health knowledge, attitude and practices of adolescents in Nigeria. SAGE Open Med. 2020;8:2050312120951066. doi: $10.1177 / 2050312120951066$. eCollection 2020.

10. Paula JS, Leite IC, Almeida AB, Ambrosano GM, Pereira AC, Mialhe FL. The influence of oral health conditions, socioeconomic status and home environment factors on schoolchildren's selfperception of quality of life. Health Qual Life Outcomes. 2012;10:6. doi: 10.1186/1477-7525-10-6.

11. Lawal FB, Taiwo JO. Making a case for formal school-based oral health promotion: oral health knowledge, attitude and practices of pupils in Ibadan, Nigeria. Int Q Community Health Educ. 2018;38(2):99-105.

12. Lu HX, Wong MC, Lo EC, McGrath C. Trends in oral health from childhood to early adulthood: a life course approach. Community Dent Oral Epidemiol. 2011;39(4):352-60.

13. Kish L. Survey sampling. New York: Wiley; 1965.

14. UNICEF. The state of the world's children 2011-executive summary: Adolescence an age of opportunity. UNICEF; 2011.

15. Sanders RA. Adolescent psychosocial, social, and cognitive development. Pediatr Rev. 2013;34(8):354-8; quiz 358-9.

16. Lawal FB, Arowojolu MO. Sociodemographic status of patients seeking routine scaling and polishing in a resource challenged environment. West Afr J Med. 2015;34(3):193-6.
17. Lawal FB, Bankole OO. Impact of untreated dental caries on daily performances of children from low social cass in an urban African population: the importance of pain. Pesqui Bras Odontopediatria Clín Integr. 2019;19:e4771. http://dx.doi.org/10.4034/pboci.2019.191.82.

18. Lawal F, Dauda M. Applicability and cross-cultural adaptation of the self-administered Child-OIDP in a rural Nigeria community. Afr J Med Med Sci. 2017;46(3):297-303.

19. Löe H, Silness J. Periodontal disease in pregnancy I. Prevalence and severity. Acta Odontol Scand. 1963;21(6):533-51.

20. Ghasemi A, Zahediasl S. Normality tests for statistical analysis: a guide for non-statisticians. Int J Endocrinol Metab. 2012;10(2):486-9.

21. Levin L, Margvelashvili V, Bilder L, Kalandadze M, Tsintsadze N, Machtei EE. Periodontal status among adolescents in Georgia. A pathfinder study. PeerJ. 2013;1:e137. doi: 10.7717/peerj.137. eCollection 2013.

22. da Silva PL, Barbosa TS, Amato JN, Montes AB, Gavião MB. Gingivitis, psychological factors and quality of life in children. Oral Health Prev Dent. 2015;13(3):227-35. doi: 10.3290/j.ohpd.a32344.

23. Antunes JLF, Peres MA, Frias AC, Crosato EM, Biazevic MGH. Gingival health of adolescents and the utilization of dental services, state of São Paulo, Brazil. Rev Saude Publica. 2008;42(2):191-9. doi: 10.1590/s0034-89102008000200002

24. Kozmhinsky VMR, Heimer M, Goes PSA. Sociodemographic factors and oral health conditions related to the impact on the quality of life of adolescents. Pesqui Bras Odontopediatria Clín Integr. 2016;16(1):35-42. doi: http://dx.doi.org/10.4034/PBOCI.2016.161.04

25. Nurelhuda NM, Ahmed MF, Trovik TA, Astrom AN. Evaluation of oral health-related quality of life among Sudanese schoolchildren using Child-OIDP inventory. Health Qual Life Outcomes. 2010;8:152. doi: $10.1186 / 1477-7525-8-152$.

26. Peres KG, Peres MA, Araujo CL, Menezes AM, Hallal PC. Social and dental status along the life course and oral health impacts in adolescents: a population-based birth cohort. Health Qual Life Outcomes. 2009;7:95. doi: 10.1186/1477-7525-7-95.

27. Barbosa TS, Tureli MC, Gavião MB. Validity and reliability of the Child Perceptions Questionnaires applied in Brazilian children. BMC Oral Health. 2009;9:13. doi: 10.1186/1472-6831-9-13.

28. Castro RdeA, Portela MC, Leao AT, de Vasconcellos MT. Oral healthrelated quality of life of 11- and 12-year-old public school children in Rio de Janeiro. Community Dent Oral Epidemiol. 2011;39(4):336-44. 